ISSN 1112-9867

\title{
PERSONAL STRATEGIC PLANNING MOBILE APPLICATION: PRELIMINARY STUDY
}

\author{
D. M. Bamasoud*, A. S. Alqhtani, A. S. Alakloby, A. H. Alakloby, N. S. Alaklobiand R. S. \\ Alshahrani
}

Computer Sciences Department, Faculty of Sciences and Home Economics, Bisha University, Bisha, Aseer, Kingdom of Saudi Arabia

Published online: 17 October 2017

\begin{abstract}
An important aspect of successful personal planning is to promote the individual to commit to his own plans. Although of the importance of personal planning in all aspects of individuals' daily life and future, failure is a predictable result of a non-well managed and written plans. Hence, smartphones nowadays become a necessity for individuals their usage in daily life has become a basic need. With the recent advances in the capabilities of smartphones and their growing penetration rate among the individuals, it is possible to take advantage of these devices to design a mobile application to promote personal strategic planning. The paper reviews relevant literature and designs an instrument to investigate the need for such mobile applications for the individuals.
\end{abstract}

Keywords: personal strategic planning; smartphones; mobile application.

Author Correspondence,e-mail: dr.bamasoud@gmail.com

doi: http://dx.doi.org/10.4314/jfas.v9i5s.8 


\section{INTRODUCTION}

Despite of the importance of personal strategic planning to individuals [1-3], individuals may encounter difficulties in accomplishing their plans. These difficulties can be caused due to: individuals' misbehavior on not committing to their own plans, not able to distinguish between planning and plans, reliance on self-experience and resistance to change. Furthermore, there are difficulties may emerge from the planning process itself and beyond the individuals' control. Such as: inflexibility, uncertainty of the future and difficulty in obtaining precise information of it. However, using accurate methods for planning reduce these difficulties.

The rapid change of information and communications technologies impacts on people's lives and induces them to use these technologies in facilitating their daily routine tasks [4-5]. Smartphones are one of those technologies that changed the way of people communication, interaction, processing information, personal management and more.

\subsection{Research Problem}

Numerous people do not plan due to lack of confidence, unawareness of the importance of planning, evading of planning obligations, inability of the person's ability to plan by his own, lack of patience, unsteadiness on predefined plans, fear of the unknown, difficulty of measuring the plan's accomplishment and the pressure caused by the person to accomplish important objectives. The individual is responsible for his own growth and success [2], therefore an individual should invest on his personal growth and set it as his first priority.

\subsection{Research Importance}

Reference [2] affirms that the main trait associated with individual's success is planning. Strategic planning is a continuous process that determines the progression of a plan's objectives. With strategic planning the individual can substantially determine the required organized activities to achieve the desired ultimate objective. Strategic planning assures the balance between resources and needs, the increment of individual efficiency and effectiveness, the control and monitoring and how individuals will do their tasks.

Furthermore, with the widespread of smartphones and their role in facilitating people's lives the deployment of such technologies in serving people is a necessity. Thus, the need arises for 
mobile applications that facilitate and monitoring the individual's plans.

Although of the importance of smartphones and strategic planning for the individuals, a lack exists in literature on promoting mobile application for personal strategic planning. Thus, in this paper, the authors focus on highlighting the importance of using smartphones in personal strategic planning. The next section will discuss the importance of personal strategic planning. Next, the paper reviews some of the recent studies of the smartphones adoption. Then, the paper discusses the development of an instrument to investigate the need for personal strategic planning mobile applications for the individuals.

\section{THEORETICAL BACKGROUND}

\subsection{Personal Strategic Planning}

Alan Lakein says "Failing to plan is planning to fail". Planning is substantial for individuals and it is contrary of random, spontaneous and improvisation. The importance of planning lies in the clarity of vision, setting goals, optimum use of resources and capabilities, setting priorities, control problems and minimize risks. Planning is a deliberated and a realistic process that create a state of balance between three elements: goals, resources and time. In other words, planning is a prediction of future's events and preparation for it, instead of expectation and observations.

Significantly, strategic planning differs from regular planning. Regular planning starts from the present and analyze predictable changes if the individual's current orientations persist. On the contrary, strategic planning has no limitation in individual's current orientations, and it starts with a leap to the future.

The key for personal strategic planning is self-organization. The main purpose of self-organization is the realization of the opportunities in daily occurrence for the individuals. The skills required for self-organization are ability to plan, organize, motivate and control [6-7]. In [6] stated that to turn the dreams into reality, an individual has first to convert these dreams into goals. As a consequence, it would be easier for individuals to accomplish their dreams.

To begin personal strategic planning, the individual has to begin self-organization [9] by: i) 
detailing the analysis of the performed tasks and time consumptions for each task, ii) carry out an analysis for inventory of time consumptions for all tasks and identification of strengths and weaknesses, iii) counting the period of time and work for each single day, iv) finally, produce a progression chart for achieved tasks periodically.

In [3] affirmed the importance of setting goals and objectives in career development. Thus, to facilitate personal career growth, the individual has to organize him/herself and set the goals and objectives. Setting the goals and objectives is a process of determining future goals and evaluation of the resources that can help in accomplishing the desired goals. In other words, planning is a process of harmonization of individual's needs and available resources, and choosing the best path among available alternative paths.

\subsection{Smartphones}

Nowadays, smartphones is viewed as a substantial communication tool $[5,10]$. Thus, the smartphones have become an integral part of many societies [8]. Therefore, extensive studies emphasized on the importance of smartphones in individuals' daily life [5, 11-12]. Various studies show that smartphones play a major role in facilitation an individual's tasks. Thus, extensive literature has addressed the importance of the smartphones in the individuals' various activities and tasks.

In [13] revealed that the usage of smartphones positively influence the academic researchers' research activities. In [14] ascertained that smartphones play affirmative role in delivery service sector. In [15] argued how smartphones shape the tourist experience for travelers.

\section{METHODOLOGY}

\subsection{Questionnaire Development and Data Collection}

A survey instrument was developed based on prior literature, graduation dissertations and analysis of mobile applications. The data collected through web-based surveys. The targeted respondents are from all age ranges and both gender, male and female. The survey was divided into four sections (refer to Table 1). The first section is for demographic details of the targeted respondents, such as: age, gender, educational level and do the respondents poses a smartphone or not. The second section is for the analysis, which represents the initial 
elements of the proposed mobile application. The third section is for the design, which concerns about the preferable features of the proposed mobile application. The last section is the development section. This section concerns about if the respondents prefer to have authorizations for other mobile application inside the proposed mobile application.

To ensure the clarity and content validity of developed instrument, two experts validated the instrument. A 3-point Likert-type scale was used. The scale ranges from 1 (agree) to 3 (disagree). Table 1 refers to the developed instrument.

Enter your results in this section, summarize the collected data and the analysis performed on those data relevant to the discourse that is to follow.After presenting the results, you are in a position to evaluate and interpret their implications especially with respect to your original hypotheses [4].

Table 1.Survey instrument

\begin{tabular}{|c|c|}
\hline Classification & Survey Items \\
\hline \multirow[t]{4}{*}{ Age } & 5 years to 12 years \\
\hline & 13 years to 18 years \\
\hline & 19 years to 23 years \\
\hline & 24 years and above \\
\hline \multirow[t]{2}{*}{ Gender } & Female \\
\hline & Male \\
\hline Educational & Primary/Secondary/High School Student \\
\hline \multirow[t]{3}{*}{ Level } & University Student \\
\hline & Employee \\
\hline & Other \\
\hline Smartphone & Yes \\
\hline possession & No \\
\hline Analysis & Do you agree on having a daily schedule for your tasks based on your future \\
\hline Construct & $\begin{array}{l}\text { goals including the various areas of life (such as career goals, study goals, } \\
\text { religion goals, and social goals, etc)? }\end{array}$ \\
\hline
\end{tabular}


Would you replace your paper-based daily schedule with the mobile application "My Vision” for scheduling your tasks and goals?

Do you expect such mobile application, My Vision app, which helps in scheduling tasks and goals would be successful among other mobile applications?

Do you expect that the mobile application "My Vision" would gain your confidence in scheduling and planning all of your tasks and goals?

Do you put priorities for your tasks that you must fulfill in your work and daily life?

Would you encourage the idea of having the mobile application "My Vision" to support your plans and future dreams?

Do you think the mobile application "My Vision" is a weak addition to mobile applications that support Arabic language and provide services for personal planning?

Design Do you agree to have some of your plans and future dreams audio recorded? Construct Do you prefer to have your plans and future dreams protected by a code and more private?

Do you prefer to have graphics and motivational phrases in the mobile application "My Vision”?

Do you encourage that the mobile application "My Vision" serves all ages categories?

Do you encourage that the mobile application "My Vision" produces a chart to illustrate the person's progression in accomplishing the planned tasks?

Do you prefer to have alarms for your plans in the mobile application "My Vision" 
Do you prefer to archive the accomplished plans?

Do you prefer to classify your plans with the ability to create a new classification of your own?

Do you prefer to have guidance notifications for first time using "My Vision"?

Do you prefer to set an image for your plans?

Development

Do you agree to have plugins in the mobile application "My Vision" for Construct persons with special needs?

Do you agree to have plugins in the mobile application "My Vision" for other mobile applications?

Do you prefer to have Feedback in the mobile application "My Vision"?

\subsection{Data Analysis}

IBM SPSS 14 statistical software was employed to carry out the statistical analysis. The descriptive statistics of the data collected and reliability test were assessed by SPSS.

A total of 60 successful responses were used in the analysis. The collected data were examined for missing data and respondents test bias. A description of the sample is provided in Table 2. 
Table 2.Sample description

\begin{tabular}{|c|c|c|c|}
\hline & Label & Frequency $(N=60)$ & Percentage(100\%) \\
\hline \multirow{2}{*}{ Gender } & Male & 9 & $15 \%$ \\
\hline & Female & 51 & $85 \%$ \\
\hline \multirow{5}{*}{ Age } & 5-12 Years & 9 & $15 \%$ \\
\hline & 13-18 Years & 3 & $5 \%$ \\
\hline & & & \\
\hline & 19-23 Years & 28 & $46.67 \%$ \\
\hline & Above 23 Years & 20 & $33.33 \%$ \\
\hline \multirow{4}{*}{ Education Level } & School & 14 & $23.33 \%$ \\
\hline & University & 28 & $46.67 \%$ \\
\hline & Employee & 10 & $16.67 \%$ \\
\hline & Other & 8 & $13.33 \%$ \\
\hline \multirow{2}{*}{ Smartphone possession } & Possess & 57 & $95 \%$ \\
\hline & Do not Possess & 3 & $5 \%$ \\
\hline
\end{tabular}

Out of the 60 respondents, 51 were females (85\%), and only 9 were males $(15 \%) .15 \%$ of the respondents aged between 5 and 12 years, 5\% aged between 13 and 18 years, $46.67 \%$ aged between 19 to 23 years and $33.33 \%$ aged above 23 years. There is $23.33 \%$ of the respondents were students (primary, secondary and high school), $46.67 \%$ of the respondents were undergraduate students, $16.67 \%$ of the respondents were employers and $13.33 \%$ classified as other. About $95 \%$ of the respondents possessed smartphone devices and only $5 \%$ of them did not.

To validate the developed instrument, the authors used SPSS14. The authors deployed scale reliability test for the proposed measures of the instrument. Internal reliability analysis helps 
to assess the goodness of fit [16]. The most popular assessment of inter-item consistency reliability is the Cronbach's alpha. Thus the Cronbach alpha test is employed for the pilot data. In [17] stated that the Cronbach's alpha value of at least 0.5 is considered good for measures. Also, in [17] stated that the Cronbach's alpha value of 0.3 and lower is considered low.

Table 3 shows the statistical results of the reliability test. The overall Cronbach's alpha for the Analysis construct is 0.520 , which is considered acceptable value. Furthermore, the analysis showed that if measure Ana7 is omitted the overall value of the Cronbach's alpha would rise to 0.522. However, the raise in Cronbach's alpha not considered high thus the measure Ana7 will be retained. In the design construct, the overall Cronbach's alpha is 0.607 which is considered good value. Further, the analysis showed that if the measure Des2 is omitted the overall value of the Cronbach's alpha would rise to 0.631 which is considered a good value. Thus, the authors will omit the measure Des2. Finally, in the design construct, the overall Cronbach's alpha is 0.460 which is considered quite low value. The analysis showed that if the measure Dev1 is omitted the overall value of the Cronbach's alpha would rise to 0.581 , which is considered a good value. Thus, the authors will omit the measure Des2.

Table 3.Survey results

\begin{tabular}{lccc}
\hline Construct & Measure & Cronbach's Alpha & Cronbach's Alpha if Item Deleted \\
\hline Analysis & & 0.520 & 0.442 \\
& Ana1 & 0.517 \\
& Ana2 & 0.503 \\
& Ana3 & 0.467 \\
& Ana4 & & 0.447 \\
& Ana5 & & 0.479 \\
& Ana6 & & 0.522 \\
Design & & & \\
& & 0.607 &
\end{tabular}


Des1

0.600

*Des2

0.631

Des3

0.581

Des4

0.590

Des5

0.539

Des6

0.566

Des7

0.584

Des8

0.508

Des9

0.610

Des 10

0.588

Development

0.460

*Dev1

0.581

Dev2

$-0.091$

Dev3

0.205

* Indicates that if item omitted, the Cronbach's alpha will be higher

\section{DISCUSSION AND CONCLUSION}

The paper highlighted the importance of personal strategic planning for individuals and how the individuals may encounter difficulties in accomplishing their plans. Furthermore, the paper highlighted the importance of information and communications technologies such as smartphones in facilitating the individuals' daily routine and tasks. Thus, this paper aims to draw an attention to the importance of how information and communications technologies represented by smartphones can facilitate the process of personal strategic planning.

The paper developed an instrument and deployed scale reliability test to assess the inter-reliability of the proposed measures. The analysis showed that overall results of the 
reliability are acceptable if the measure Dev1 from the Development construct is omitted. Other constructs, Analysis and Design, the analysis results showed that both of the constructs are scale reliable.

\section{FUTURE WORK}

Future work will focus on conducting the main study with the refined the proposed instrument. The research is planned to explore further the theoretical and practical aspects of how smartphones' mobile applications for personal strategic planning can facilitate the process of planning for individuals. Moreover, the research is planned to explore the influence of external and internal motivations on the personal strategic planning.

\section{ACKNOWLEDGEMENTS}

The authors: A. S. Alqhtani, A. S. Alakloby, A. H. Alakloby, N. S. Alaklobi, and R. S. Alshahrani would like to express their deep gratitude to: (i) Bisha University and Ministry of Education for their support in pursuing their undergraduate study, (ii) $\mathrm{Mr}$. FahadRajehAljunaybi for his continuous support and constructive assistance, and (iii) the first author Dr. D. M. Bamasoud, who is assigned as their supervisor, for her generous support and constructive suggestions during pursuing their graduation project.

\section{REFERENCES}

[1] Fowler C.Personal strategic planning: A roadmap for change. In 41st Annual Meeting National Organization of Nurse Practitioner Faculties, 2015

[2] Garcia E V.Strategic planning: A tool for personal and career growth. Heart Asia, 2016, $8(1): 36-39$

[3] ManclK. Framework for mentoring East Asian women scientists and engineers. Ohio Journal of Science, 2017, 116(2):28-33

[4] Lee S Y. Examining the factors that influence early adopters' smartphone adoption: The case of college students.Telematics and Informatics, 2014, 31(2):308-318 
[5] BamasoudD M, IahadN A, Rahman AA.Self-efficacy and its impacts on academic researchers' absorptive capacity in smart phones acceptance: Conceptual paper.In IEEEInternational Conference on Research and Innovation in Information Systems, 2013,pp. $275-280$

[6] KirillovA V, TanatovaD K, VinichenkoM V, MakushkinS A.Theory and practice of time-management in education. Asian Social Science, 2015, 11(19):193-204

[7] VinogradovaM V, KryukovaE M, KulyaminaO S, VapnyarskayaO I, SokolovaA P.Approaches to the study of the status and trends of drug abuse, rehabilitation and reintegration of drug users.Biosciences Biotechnology Research Asia, 2014, 11(3):1505-1514

[8] Blackwell C K, LauricellaA R, WartellaE. Factors influencing digital technology use in early childhood education.Computers and Education, 2014, 77:82-90

[9] ArkhangelskiiG. A. Time drive: How to have time to live and work. Moscow: Mann, Ivanov and Verber Publishers, 2010

[10] ZulkeflyS N, BaharudinR. Mobile phone use amongst students in a university in Malaysia: Its correlates and relationship to psychological health. European Journal of Scientific Research, 2009, 27(2):206-218

[11] PheeraphuttharangkoonS. The adoption, use and diffusion of smartphones among adults over fifty in the UK. Phd thesis, England: University of Hertfordshire, 2015

[12] ElogieA. A. Factors Influencing the adoption of smartphones among undergraduate students in Ambrose Alli University Ekpoma, Nigeria.Library Philosophy and Practice, 1257: $1-14$

[13] BamasoudD M, IahadN A, Rahman AA. Academic researchers' absorptive capacity influence on collaborative technologies acceptance for research purpose: Pilot study. Modern Applied Science, 2014, 8(6):161-169

[14] Chen K, Chen J V, Yen D C. Dimensions of self-efficacy in the study of smart phone acceptance.Computer Standards and Interfaces, 2011, 33(4):422-431

[15] Wang D, Xiang Z, FesenmaierD R. Smartphone use in everyday life and travel. Journal of Travel Research, 2016, 55(1):52-63 
[16] CavanaR, DelahayeB, SekaranU.Applied business research: Qualitative and quantitative methods.Queensland: John Wiley and Sons, 2001

[17] Schmidt F L, Hunter J. General mental ability in the world of work: Occupational attainment and job performance. Journal of Personality and Social Psychology, 2004, $86(1): 162-173$

\section{How to cite this article:}

Bamasoud D. M., Alqhtani A. S., Alakloby A. S., Alakloby A. H., Alaklobi N. S., and Alshahrani R. S. Personal strategic planning mobile application: preliminary study. J. Fundam. Appl. Sci., 2017, 9(5S), 88-100. 